\title{
Behavioral Risk Factors for Non-Communicable Disease among Factory Employees in Faridabad; Haryana
}

\author{
Jamatia B, ${ }^{1}$ Anand $K_{,}{ }^{2}$ Kapoor SK, ${ }^{2}$ Pandey $\mathrm{RM}^{3}$ \\ ${ }^{1}$ School of Health Sciences, Indira Gandhi National Open University, Maidan Garhi, New Delhi, Indian, ${ }^{2}$ Centre for Community \\ Medicine, ${ }^{3}$ Department of Biostatistics, AllMS, New Delhi, India.
}

\section{ABSTRACT}

Introduction: In developing countries like India, in addition to the infectious diseases, noncommunicable diseases are emerging as significant causes of morbidity and mortality. Workplaces present a setting which is appropriate for intervention for adults in a community. The aim of this study is to assess the knowledge, attitude and prevalence of selected risk factors for non-communicable diseases.

Methods: A cross sectional study was conducted among the regular employees of the factories. Smoking, alcohol consumption, dietary intake and physical activity were measured through interview schedules and height, weight and blood pressure were also measured by standard instrument. An awareness generation program was pre-tested.

Results: A total of 545 employees were interviewed. Among them 307 (56.3\%) and 238 (43.7\%) were manual and non-manual workers respectively. Most of the employees knew [smoking as a risk factor for hypertension $(55.2 \%)$, heart attack $(61.1 \%)$ and cancer $(78.7 \%)$; Alcohol as a risk factor for hypertension $(72.1 \%)$, heart attack (73.9\%), cancer ( 54.9\%); Physical inactivity as a risk factor for hypertension $(82.6 \%)$, heart attack $(78.5 \%)$, diabetes $(60.4 \%)$ and high fat diet as a risk factor for hypertension $(67.2 \%)$, heart attack $(64.8 \%)$ ] that these risk factors lead to different noncommunicable diseases. The prevalence $(95 \% \mathrm{CI})$ of the risk factors is as follows: male current smoker [40.7\% (36.4-45.3)], current alcohol consumption [31.0\% (27.2 - 35.1)], sedentary activity [41.2\% (37.0 - 45.5)], high fat intake [93.7\% (90.2 - 95.5)], over weight [26.9\% (23.2 - 30.9)] ; and hypertension [21.0\% (17.62 - 24.6)]

Conclusions: This study showed that the risk factors for non-communicable diseases are prevalent in factory employees. Implementation of the risk factors control programme is desirable and there is an interest among employees and management.

Key Words: alcohol consumption, diet, over weight, physical activity, risk factor, smoking

\section{INTRODUCTION}

After the era of pestilence and famine and the era of receding pandemics, Omran has described an era of degeneration and man made diseases where there is an increase in the prevalence of cardiovascular diseases, cancer, diabetes and other degenerative diseases. ${ }^{1}$ It was estimated that in 2005 non communicable diseases

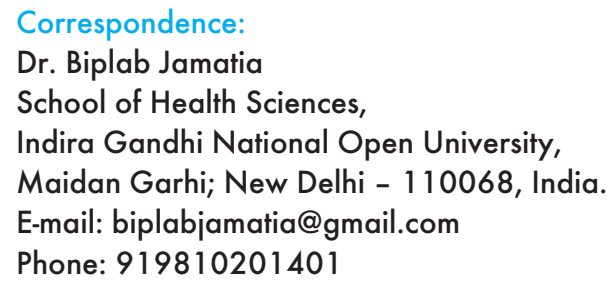


(NCDs) accounted for 5.4 million (53\%) of all deaths $(10,362,000)$ in India. ${ }^{2}$ Risk factors surveillance can help in monitoring the progress of the disease epidemic and the efficacy of the intervention programmes. Workplace provides a useful platform to address many of these risk factors for adults as they spend a good proportion of their day in these settings.

The aim of this study was to find out the knowledge, attitude and prevalence of selected risk factors (smoking, alcohol, physical activity, dietary intake, overweight and hypertension) for non-communicable diseases among factory employees and implementation of risk factors control programme among them and exploring the possibilities of instituting a workplace intervention.

\section{METHODS}

A cross sectional study was conducted in three factories in the Faridabad district, Haryana from July 2001 to June 2003. Ethical approval and participants consent was taken. Depending on the nature of the work these employees were categorized into manual worker and non-manual worker groups. Those employees who were involved in labour intensive work were manual workers and employees who were not related to labour intensive work were categorized into non-manual workers group. All the regular employees of the factories were included but the contractual employees were excluded from this study.

Sample size was calculated on the basis of alcohol consumption, which was expected to be the least based on available information. The prevalence was taken to be $36 \pm 6 \%$ (absolute precision). ${ }^{3}$ The sample (n) size calculated was 256 for each group of manual workers and non-manual workers.

Based on the employee strength, $25 \%$ of manual workers and $50 \%$ of the non-manual workers were randomly chosen from factory I. A list of all the employees of factory I had been taken from the factory rolls at the beginning of the study and classified as manual and non-manual workers. Randomly selected employees were informed one week before the date of interview. All the regular employees of factory II and factory III were interviewed.

The WHO STEP wise approach ${ }^{4}$ Interview Schedule was suitably modified according to our situation and administered. This interview schedule had different components like; demographic, smoking, alcohol consumption, physical activity, dietary pattern, fat intake, knowledge and attitude related to above the mentioned risk factors of non-communicable diseases.

\section{Some definitions that has been used in the study}

Current Smoker: People who have smoked more than 100 cigarettes or 100 bidis in their lifetime and smoked currently were taken as current smokers.
Past Smoker: A person who smoked more than 100 cigarettes or 100 bidis but has not smoked in the last one year is a past smoker.

Alcohol Intake: A person who has consumed alcohol in the last six months was taken as an alcohol user. They were again categorized into those who consume alcohol on a; weekly, monthly and six monthly basis according to the frequency of intake.

Physical activity: Physical activity was categorized into three categories. Sedentary physical activity refers to an activity that does not change any breathing pattern. Any activity or work carried out at least 10 minutes at a stretch that leads to the shortening of breath of a normal individual moderate type of physical activity. Heavy physical activities refer to those activities that make harder physical effort and make change in vigorous breathing pattern than moderate type of physical activity.

High fat intake: More than 20 grams visible fat intake per person per day was defined as high fat intake. ${ }^{5}$

Overweight: A person who has a BMI of 25.0 to 29.99 was taken as overweight. ${ }^{6}$

Hypertension: A person with systolic blood pressure $\geq 140 \mathrm{mmHg}$ and diastolic blood pressure $\geq 90$ $\mathrm{mmHg}$ or a person who is on anti hypertensive a drug irrespective of their blood pressure status was taken as a hypertensive. ${ }^{7}$

Only one author (BJ) carried out all the interviews. Informed consent of both the employers and the employees was taken. Data were entered and analyzed with the Epi Info version 1.0.4. Chi-square test was applied to find out the difference between these two groups. For risk factors, prevalence and $95 \%$ confidence interval was calculated. Test of proportions was used to compare the difference in two proportions. Student's $t$ test was used to compare mean in two groups. In this study, p-value less than 0.05 has been considered as statistically significant.

\section{RESULTS}

In this study a total of 545 employees were interviewed. Majority 486 (89.2\%) of the participants were men while only $59(10.8 \%)$ were women. Of the respondents, 307 (56.3\%) and 238 (43.7\%) were manual worker and non-manual worker respectively. Most of the employees $335(61.5 \%)$ were 40 years and above. The mean age of the manual workers was higher as compared to the non-manual workers $(42.2 \pm 10.9$ SD Vs $39.9 \pm 10.7$ SD $P<0.00001)$.

Refusal rate was negligible with only two respondents refusing to be interviewed. Of the study subject, 452 
$(82.9 \%)$ employees were residents of urban areas while only $93(17.1 \%)$ belonged to the rural areas. Most of these employees $(86.5 \%)$ were married, $323(59.3 \%)$ of the employees were educated up to secondary level and only $4.2 \%$ were illiterate. More than half (55.2\%) of the participant's total family income per month was within Rs. 5000 - 9999. Only $16.1 \%$ participants had a total family income more than Rs. 15000/- per month.

\section{Knowledge of risk factors and diseases (Table 1)}

Most of the respondents knew that smoking is a risk factor for many disease.

Smoking was largely related to cancer $(78.7 \%)$ and much less to cardiovascular events (22.9\%-61.1\%). Alcohol was more often related to Heart disease $(73.9 \%)$ rather than cancer $(54.9 \%)$ or stroke $(45.5$ $\%)$. Physical inactivity and high fat intake were also linked by the respondents to heart diseases rather than stroke or cancer. Overall, the link between these risk factors and stroke and diabetes was least well known to the respondents. Non-manual workers had better understanding of the role of risk factors in disease causation.

\section{Prevalence of risk factors (Table 2)}

Tobacco use: Among the male employees the prevalence of current smoking was $40.7 \%(95 \% \mathrm{Cl}$; 36.4-45.3). When the male employees were stratified according to the nature of work, the prevalence of smoking in male manual workers was $47.8 \%(95 \% \mathrm{Cl} ; 41.7-53.9)$ as against $31.8 \%(95 \% \mathrm{Cl} ; 25.6-38.5)$ in male non-manual workers. $(P=0.003)$. None of the female employees were current smokers or ever smokers. Manual worker employees on an average started smoking at an earlier age compared to non-manual worker employees $(21.4 \pm 7.5$ years $V s 23.1 \pm 6.6$ years; $P=0.06)$. The prevalence of bidi consumption was higher among manual workers $(46.7 \%$ Vs $14.9 \%)$ but cigarette consumption was higher among non-manual workers (15.1\% Vs $29.0 \%)$. In case of khaini (10.7\% Vs $2.8 \%)$ and guthka $(6.2 \% \mathrm{Vs} 4.2 \%)$ prevalence of consumption was higher among manual workers. The consumption of mean number of bidi per day and cigarette per day among the employees were $11.2 \pm 9.6$ and $6.8 \pm 7.9$ respectively. The prevalence of smokeless tobacco use was $10.1 \%(95 \% \mathrm{Cl} ; 7.8-13.0)$. The prevalence of smokeless tobacco use was higher in manual workers (14.3\%; $95 \% \mathrm{Cl} ; 10.7-18.9)$ as compared to nonmanual workers $(4.6 \% ; 95 \% \mathrm{Cl} ; 2.3-8.1)$, which was statistically significant $(P=0.0002)$. The mean numbers of khaini packet per day among the employees were less than one packet $(0.7 \pm 0.5)$. The mean number of guthka packet per day among them was $1.1( \pm 0.7)$ packet. Average duration (years) of smoking among current smokers were higher among manual workers $(24.4 \pm 10.6)$ as compared to non-manual workers
$(20.9 \pm 12.0)$ and it was statistically significant $(\mathrm{P}=0.03)$.

Among the employees $94.9 \%$ (95\% Cl; 92.6-96.5) of the employees strongly agreed that smoking was injurious to health. Nearly the same percentage (96.1\%; 95\% $\mathrm{Cl}$; 94.1-97.5) of the participants strongly agreed that passive smoking was also injurious to health. Among the employees who were currently using tobacco 156 $(66.7 \%)$ of them had thought of quitting tobacco. At the same time subjects who had given a thought to quitting smoking, $121(77.6 \%)$ had tried to give up tobacco and failed.

Alcohol use: The prevalence of alcohol intake among male employees was $34.6 \%(95 \% \mathrm{Cl}$; 30.4-39.0). The prevalence of alcohol intake was less in manual workers group as compared to the non-manual workers group (29.6\% Vs $32.8 \% ; P=0.12)$. About two thirds $(63.7 \%)$ of the consumers of alcohol, were consuming alcohol every month. Only $18.3 \%$ of the drinkers were consuming alcohol weekly. The difference of frequency of alcohol consumption between manual workers and non-manual workers was not significant $(P=0.4)$. Out of these who consumed alcohol only $33(19 \%)$ of them had ever thought of quitting alcohol. Among those who had given thought, this $24(70.6 \%)$ had already tried to give up alcohol.

Physical inactivity: The prevalence of sedentary physical activity in male non-manual workers 169.6\%; 95\% $\mathrm{Cl}=63.5-75.8)$ was higher as compared to manual workers $(6.3 \% ; 95 \% \mathrm{Cl}=3.4-9.2)$. But incase of female employees it was reverse $(100 \% \mathrm{Vs} 95.8 \%)$ and most of them were sedentary in nature. Approximately one fourth of the manual workers $(25.8 \% ; 95 \% \mathrm{Cl}=20.6-30.1)$ and non-manual workers $(27.6 \% ; 95 \% \mathrm{Cl}=21.6-33.5)$ were doing moderate type of physical activity.

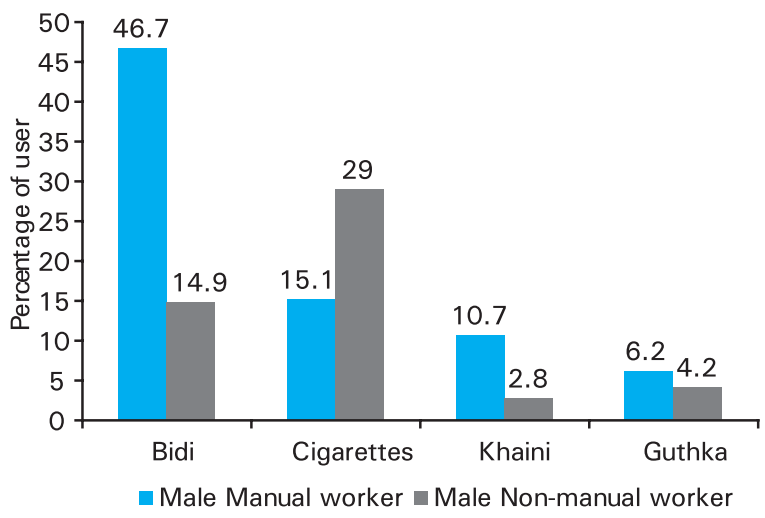

Figure 1. Percentage of using different types of tobacco products among male workers. 
Jamatia et al. Behavioral Risk Factors for Non-Communicable Disease among Factory Employees in Faridabad; Haryana

Table 1. Correct knowledge of risk factors in causing different non-communicable diseases.

\begin{tabular}{|c|c|c|c|c|}
\hline Risk factors & Smoking (\%) & Alcohol(\%) & Physical inactivity (\%) & High fat diet $(\%)$ \\
\hline \multicolumn{5}{|l|}{ Hypertension } \\
\hline Manual worker & $158(51.5)$ & $200(65.2)$ & $230(74.9)$ & $185(60.3)$ \\
\hline Non-manual worker & $143(60.1)$ & $193(81.1)$ & $220(92.4)$ & $181(76.1)$ \\
\hline Total & $301(55.2)$ & $393(72.1)$ & $450(82.6)$ & $366(67.2)$ \\
\hline \multicolumn{5}{|l|}{ Heart attack } \\
\hline Manual worker & $160(52.1)$ & $204(66.5)$ & $219(71.3)$ & $172(56.0)$ \\
\hline Non-manual worker & $173(72.7)$ & $199(83.6)$ & $209(87.8)$ & $181(76.1)$ \\
\hline Total & $333(61.1)$ & 403 (73.9) & $428(78.5)$ & $353(64.8)$ \\
\hline \multicolumn{5}{|l|}{ Stroke } \\
\hline Manual worker & $64(20.8)$ & $126(41.1)$ & $123(40.1)$ & $64(20.8)$ \\
\hline Non-manual worker & $61(25.6)$ & $122(51.3)$ & $101(42.4)$ & $82(34.5)$ \\
\hline Total & 125 (22.9) & $248(45.5)$ & $224(41.1)$ & $146(26.8)$ \\
\hline \multicolumn{5}{|l|}{ Cancer } \\
\hline Manual worker & $215(70.0)$ & $172(56.0)$ & $79(25.7)$ & $42(13.7)$ \\
\hline Non-manual worker & 214 (89.9) & $127(53.4)$ & $39(16.4)$ & $21(8.8)$ \\
\hline Total & $429(78.7)$ & 299 (54.9) & $118(21.7)$ & $63(11.6)$ \\
\hline \multicolumn{5}{|l|}{ Diabetes } \\
\hline Manual worker & - & $114(37.1)$ & $171(55.7)$ & $83(27.1)$ \\
\hline Non-manual worker & - & $68(28.7)$ & $158(66.4)$ & $81(34.0)$ \\
\hline Total & - & $182(33.4)$ & $329(60.4)$ & $146(30.1)$ \\
\hline
\end{tabular}

Table 2. Prevalence of behavioral risk factors of non-communicable diseases among employees.

\begin{tabular}{lllllll}
\hline Risk factor status & \multicolumn{2}{l}{ Manual worker (\%) } & \multicolumn{2}{l}{ Non-manual worker (\%) } & \multicolumn{2}{l}{ Total (\%) } \\
& Male & Female & Male & Female & Male & Female \\
\hline Current smoker & $130(47.8)$ & - & $68(31.8)$ & - & $198(40.7)$ & - \\
Past smoker & $26(9.6)$ & - & $22(10.3)$ & - & $48(9.9)$ & - \\
Current oral tobacco user & $44(16.2)$ & - & $11(5.1)$ & - & $55(11.3)$ & - \\
Past oral tobacco user & $2(0.7)$ & - & $2(0.9)$ & - & $4(0.8)$ & - \\
Currently consuming Alcohol & $91(35.4)$ & - & $77(36.0)$ & $1(4.2)$ & $168(34.5)$ & $1(1.7)$ \\
Consumed Alcohol in the past & $33(12.1)$ & - & $14(6.5)$ & - & $47(9.7)$ & - \\
Physical inactivity & $17(6.3)$ & $35(100)$ & $149(69.6)$ & $23(95.8)$ & $166(34.2)$ & $58(98.3)$ \\
High fat intake (>20 gm visible fat) & $252(92.6)$ & $35(100)$ & $200(93.4)$ & $24(100)$ & $452(93.0)$ & $59(100)$ \\
\hline
\end{tabular}

Table 3. Prevalence of overweight and hypertension among the workers

\begin{tabular}{lccc}
\hline & $\begin{array}{c}\text { Manual Workers } \\
(\mathbf{n}=\mathbf{3 0 6})(\%)\end{array}$ & $\begin{array}{c}\text { Non-Manual Workers } \\
(\mathbf{n}=\mathbf{2 3 7})(\%)\end{array}$ & $\begin{array}{c}\text { Total Employees } \\
(\mathbf{n}=\mathbf{5 4 3})(\%)\end{array}$ \\
\hline Over weight (BMI 25.0 - 29.99) & $64(20.9)$ & $82(34.6)$ & $146(26.9)$ \\
Obese (BMI > 30.0) & $17(5.6)$ & $13(5.5)$ & $30(5.5)$ \\
Hypertensive (\%) & $59(19.0)$ & $55(23.1)$ & $114(21.0)$ \\
\hline
\end{tabular}

Two female employees were pregnant. 
Inappropriate diet: The prevalence of high fat intake in male manual workers and male non-manual workers was $96.2 \%(95 \% \mathrm{Cl}=92.1-99.3)$ and 93.4 $(95 \%=89.6-97.8)$ respectively. All female employees were consuming higher fat than the recommended amount. The mean per capita oil intake among manual workers employees has slightly less in comparison to the non-manual workers $(46.7 \pm 17.2$ SD Vs $47.2 \pm 15.8$ S.D), but it was not statistically significant $(P=0.7)$. Regarding ghee intake; $46.4 \%$ and $37.2 \%$ of the participants moderately agreed and strongly agreed that ghee is good for health respectively. Less than one third $(31.1 \%)$ of the employees thought of reducing ghee in their diet.

Ghee was the commonest forms of fat intake by most of the employees $(86.4 \% ; 95 \% \mathrm{Cl}=83.5-89.3)$ followed by mustard oil $(63.1 \% ; 95 \% \mathrm{Cl}=59.1-67.2)$ and then refined oil $(40.7 \% ; 95 \% \mathrm{Cl}=36.6-44.8)$. Nearly three fourths $(73.8 \% ; 95 \% \mathrm{Cl}=70.1-77.4)$ of the participants were taking milk every day. More than half of the employees $(66.9 \% ; 95 \% \mathrm{Cl}=63.1-70.9)$ were taking green leafy vegetable at least once a week. One third of the employees $(33.2 \% ; 95 \% \mathrm{Cl}=29.2-37.2)$ were taking fruits at least once a week. There were significant differences between manual workers and non-manual workers in intake of milk $(P=0.006)$, meat $(P=0.001)$, chicken $(P=0.013)$, fish $(P=0.002)$, green leafy vegetable $(P=0.0008)$ and fruits $(P<0.0001)$, although there was no significant difference in the intake of eggs $(P=0.53)$.

Obesity: The prevalence of over weight people among factory employees was $26.9 \% \quad 195 \% \quad \mathrm{Cl}=23.2 \%-$ $30.9 \%)$. The prevalence of obesity among factory employees was $5.5 \%(95 \% \mathrm{Cl}=3.8 \%-7.9 \%)$. The prevalence of overweight among non-manual workers was higher than manual workers $(34.6 \%$ Vs $20.9 \%$; $\mathrm{P}=0.2$ )

High Blood pressure: The prevalence of high blood pressure was $21.0 \%(95 \% \mathrm{Cl}=17.6 \%-24.6 \%$ among factory employees). The prevalence of hypertension was higher in male employees as compared to the female employees (23.0\% Vs $3.4 \%)$. The prevalence of hypertension was higher in non-manual workers as compared to manual workers $(23.1 \%$ Vs $19.0 \% ; P=0.2)$.

\section{Assessment of Feasibility of Intervention}

The managements of all the three factories were requested to permit implementation of a health intervention package for their employees, after the study was completed. The factory managers agreed on the basis that intervention needs to be designed such that its implementation does not lead to much loss of production time. The results of the survey were shared with the management and the employees. Various methods of intervention like health talk; role- play, power point presentation and poster presentation etc. were discussed with factory managers keeping in mind their concern for loss of production time. This was followed by open forum for discussion and answering of individual queries. The response of the employee was overwhelming clearly indicating a need for provision of information on these diseases to the workers. However, the management was more concerned with productivity.

\section{DISCUSSION}

This paper describes the status of common major NCD risk factors among employees of three industrial units in Faridabad. Faridabad is an Industrial town and addressing lifestyle diseases comprehensively would involve addressing workplace settings like the one studied here.

Most of the employees knew that tobacco consumption, excessive alcohol consumption, physical inactivity and high fat intake could lead to various non-communicable diseases like hypertension, heart disease, diabetes mellitus, cancer etc. Non-manual workers were more aware in comparison to the manual workers. And there were significant differences ( $p$ value $<0.00001$ ) of knowledge between these two groups. In Delhi, Usha Srivastava (1995) found that $54.3 \%$ of study population knew that smoking was a risk factors for coronary heart disease. ${ }^{8}$ Tiwari $\mathrm{R}$ et al reported that $96.6 \%$ of the rural population of Kerala knew that tobacco use is harmful for health, but only $22.5 \%$ of the subjects knew that it causes cardiovascular diseases. ${ }^{9}$

High prevalence of tobacco use (smoked and smokeless) has been reported from many other surveys among employees of industrial units. Prabhakaran D et al reported that the prevalence of current smoking among employees aged 20-59 years of a large industry near Delhi $(n=2935)$ was $36 \%(34 \%-38 \%) .{ }^{10}$ Reddy KS, et al conducted a baseline cross-sectional survey (as part of a CVD surveillance programme) of industrial populations $(n=19,973)$ aged $20-69$ years from 10 companies across India, and reported that the $40.2 \%$ of men and $14.9 \%$ of women reported current tobacco use. ${ }^{11} \mathrm{~A}$ cross-sectional study was conducted by Medhi GK et al among tea garden youths (age 15-24 years) of Assam and found that the smoking rate was only $2.2 \%$ $(4.7 \%$ in males, $0.5 \%$ in females). However, $52.5 \%$ of the study population used non-smoked tobacco $(56.9 \%$ males, $49.6 \%$ females). ${ }^{11}$ Medhi GK et al reported that the prevalence of alcohol consumption among the tea garden youths (age 15-24 years) of Assam was 32.2\% (43.9\% males, $24.6 \%$ females). ${ }^{11}$

The findings of significant tobacco and alcohol use among the employees, the realization of its harmful effects and failed efforts at quitting indicate a need for tobacco and alcohol cessation programs in this setting. 
Prabhakaran $D$ et al reported that the prevalence overweight (BMI $\geq 25 \mathrm{~kg} / \mathrm{m}^{2}$ ) among employees aged $20-59$ years of a large industry near Delhi $(n=2935)$ was $35 \%(95 \% \mathrm{Cl}$ : $33 \%-37 \%) .{ }^{10}$ Reddy $\mathrm{KS}$, et al conducted a baseline cross-sectional survey (as part of a CVD surveillance programme) of industrial populations ( $n=19,973$ ) aged $20-69$ years from 10 companies across India, and reported that the overall prevalence of most risk factors was high, with $50.9 \%$ of men and $51.9 \%$ of women being overweight. ${ }^{11}$

High intake of fat in their diet and high rates of obesity were found. The use of canteens for lunch was varied. While in two of these everybody was taking lunch from the canteen, in one factory most of the manual workers $(72.5 \%)$ and only a few $(4 \%)$ of the non-manual workers were taking meals from the factory canteen. This does provide us with an opportunity to promote healthier alternatives for lunches in the subsidized canteens of the industries setting. It is also time to change the misperception that all factory employees are physically active. Efforts are needed to promote physical activity at workplace as leisure time physical activity is nonexistent in our community especially in the social group that was studied here.

Prabhakaran D et al reported that the prevalence of hypertension among employees aged 20-59 years of a large industry near Delhi $(n=2935)$ was $30 \%$ (28\%-32\%). ${ }^{10}$ Reddy KS, et al conducted a baseline cross-sectional survey (as part of a CVD surveillance programme) of industrial populations ( $n=19,973$ ) aged 20-69 years from 10 companies across India, and reported that the overall prevalence of self-reported prevalence of hypertension $(10.9 \%)$ which was lower than when measured clinically and bio-chemically $(27.7 \%,)^{11}$

Traditionally Industrial health in India has focused only on occupational diseases. There is a need for a paradigm shift in thinking. It is time to promote health comprehensively at workplace settings. The intervention programme conducted in this study has shown that such an intervention is feasible but it has to be modified according to the local needs. This intervention has since then be followed up with formulation of guidelines for healthy workplace in collaboration with Faridabad Industries Association. The management needs to be convinced that these activities are investments rather than expenditure for them, as healthy employees will lead to increased work out put in future.

\section{CONCLUSIONS}

This study showed that the risk factors for noncommunicable diseases are prevalent in factory employees. Implementation of the risk factors control programme is desirable and there is an interest among employees and management.

\section{ACKNOWLEDGEMENTS}

We would like to thank to all the employers, personnel managers and employees of the factories. My sincere thanks to HRIDAY and SHAN group.

\section{REFERENCES}

1. Omran AR. The epidemiological transition. A theory of epidemiology of population changes. Millibank Memorial Fund Quarterly 1971;U.49:509-538.

2. Ministry of Health, Government of India. Annual Report 2006-07. New Delhi: Ministry of Health and Family Welfare; Govt. of India; 2007.

3. Sundaram KR, et al. Alcohol abuse in a rural community in India. Part I epidemiology study. Drug Alcohol Depend. 1984;14(1):27-36.

4. The WHO STEP wise Approach to Surveillance (STEPS) of NCD Risk Factors: STEPS Instruments (CORE and Expanded). Geneva: WHO; Aug 2001.

5. Beegom R; Singh RB. Association of higher saturated fat intake with higher risk of hypertension in urban population of Triandrum in South India. International Journal of Cardiology. 1997; 58: 63-70.

6. World Health Organization. WHO 2000 Tech Rep Ser, No. 894. New Delhi: WHO; 2000.

7. Chobanian AV, Bakris GL, Black HR, Cushman WC, Green LA, Izzo JL Jr, et al. The Seventh Report of the Joint National Committee on Prevention, Detection, Evaluation, and
Treatment of High Blood Pressure: the JNC 7 report. JAMA. 2003 May 21;289(19):2560-72.

8. Srivastava U. Health beliefs in relation to coronary heart disease, 1995 Apr; Thesis- personal communication.

9. Tiwari R, Deb P, Debbarma A, Chaudhuri R, Chakraborty A, Lepcha $\mathrm{M}$, et al. Tobacco use and cardiovascular disease: a knowledge, attitude and practice study in rural Kerala. Indian J Med Sci. 2006 Jul;60(7):271-6.

10. Prabhakaran D, Shah P, Chaturvedi V, Ramakrishnan L, Manhapra A, Reddy KS. Cardiovascular risk factor prevalence among men in a large industry of northern India. Natl Med J India. 2005 Mar-Apr; 18(2):59-65.

11. Reddy KS, Prabhakaran D, Chaturvedi V, Jeemon $\mathrm{P}$, Thankappan KR, Ramakrishnan L, et al. Methods for establishing a surveillance system for cardiovascular diseases in Indian industrial populations. Bull World Health Organ. 2006 Jun;84(6):461-9.

12. Medhi GK, Hazarika NC, Mahanta J. Tobacco and alcohol use among the youth of the agricultural tea industry in Assam, India. Southeast Asian J Trop Med Public Health. 2006 May;37(3):581-6. 